\title{
SOÑAR EL PORVENIR, UN ACTO DE CREACIÓN INFANTIL
}

Dreaming the Future, an Act of Children's Creation

\section{Fernande Marie Françoise Brisson \\ brisson50@yahoo.fr \\ Sede de Cuernavaca Morelos de la UPN}

RESUMEN: Este trabajo muestra los resultados de una investigación-intervención para Soñar el porvenir. Su peculiaridad consistió en crear situaciones de indagación para visibilizar los imaginarios instituidos restrictivos en el soñar, por los arraigos materiales y simbólicos de las condiciones sociales, culturales y económicas de vulnerabilidad en los niños y niñas.

La investigación-intervención se realizó entre 2014 y 2016 durante los últimos grados de Primaria, en una escuela vespertina ubicada en una zona marginal-industrial en Cuernavaca, Morelos, México.

Se sostiene que el acto de creación de escenarios de porvenir en el infante potencia su transitar de la niñez a la adultez, mediante procesos que operan como recursos para establecer un proyecto de vida. El trabajo consistió en diseñar cada situación para indagar los modos de percibir el mundo y, simultáneamente, imaginar escenas de porvenir. Así los ángulos de investigación-intervención al articularse dislocan cánones convencionales de investigación. Cada situación al encadenarse tácticamente produjo trayectorias de configuración para un imaginario radical (Castoriadis, 2002) que desplegaron sueños de porvenir.

Palabras Clave: sueños, porvenir, alteridad, intervención educativa.

RESUM: Aquest treball mostra els resultats d'una investigació-intervenció per Somiar el futur. La seua peculiaritat va consistir a crear situacions d'indagació per visibilitzar els imaginaris instituïts restrictius en el fet de somiar, pels arrelaments materials i simbòlics de les condicions socials, culturals i econòmiques de vulnerabilitat en els nens i nenes. 
La investigació-intervenció es va realitzar entre 2014 i 2016 durant els últims graus de Primària, en una escola vespertina situada en una zona marginal-industrial a Cuernavaca, Morelos, Mèxic.

Se sosté que l'acte de creació d'escenaris de futur en l'infant potencia el seu transitar de la infantesa a l'adultesa, mitjançant processos que operen com a recursos per establir un projecte de vida. El treball va consistir a dissenyar cada situació per indagar les maneres de percebre el món i, simultàniament, imaginar escenes de futur. Així els angles d'investigació-intervenció a articular-disloquen cànons convencionals d'investigació. Cada situació a encadenar-tàcticament va produir trajectòries de configuració per a un imaginari radical (Castoriadis, 2002) que van desplegar somnis de futur.

Paraules clau: somnis, avenir, alteritat, intervenció educativa.

ABSTRACT: This article presents the results of an investigation-intervention Dreaming the future, which consisted of creating situations of ludic inquiry to reveal instituted social imaginary (Castoriadis), expressed as restrictions to the act of dreaming caused by the symbolic and material roots of the social, cultural and economic conditions of vulnerability among children.

The investigation and intervention took place from 2014 to 2016 with boys and girls in the fifth and sixth grades in an elementary school located in a marginal industrial zone in Cuernavaca, Morelos, Mexico.

We start from the premise that creating future scenarios enhances the transition from childhood to adulthood though processes that act as resources to establish a life project. In the investigation-educational intervention the children were given exercises in which they outlined and followed trajectories for their dreams of the future, juxtaposing imagination and reality. Situations were designed to explore the way they perceive the world, and that at the same time offered other possibilities for imagination. One situation triggered other situations, creating configuration trajectories for a radical imaginary (Castoriadis), from which their dreams of the future unfolded.

KEYWORDS: dreams, future, otherness, educational intervention. 


\section{Introducción}

El sueño de porvenir propicia la capacidad de colocarse en escenarios imaginarios para crear mundos alternos, no se trata de una simplemente actividad cerebral, sino de una función creadora de porvenir.

El corpus conceptual y metodológico se sustenta con los supuestos de Castoriadis, $(2002,1999,1975)$ quien ha estudiado los engarces entre la imaginación del individuo y el imaginario de la sociedad en la que está inmerso, así como en algunos otros autores. «La imaginación radical hace surgir (...) un "contenido", un flujo representativo/afectivo/intencional espontáneo inagotable ajeno a nuestro control», Castoriadis (1999, p. 5). Además de los planteamientos de Berger y Luckman (2003) sobre los procesos de socialización primaria y secundaria. Ana María Fernández (2002), apuntala con una concepción del campo de lo grupal como una analítica para problematizar los fenómenos simbólicos que propician filiaciones y significaciones superando la visión reducida de grupo. Con las figura de dispositivo, trayecto, devenir de Deleuze (1993) hay un apuntalamiento como caja de herramientas que habilitó el dispositivo de investigación-intervención para una temática que ha sido poco abordada en el terreno educativo. Se asume que al situarse en el análisis de la singularidad de la experiencia producida por esos niños y niñas se construyeron nuevos recursos ontológicos y epistémicos para pensar ejercicios similares sin pretensiones de generalización.

En una revisión sobre el tema se destacan cinco investigaciones que tocan distintos aspectos sobre la temática. En un período que va del 2006 al 2012 destacan trabajos realizados en Brasil, Canadá y Colombia, así como en España, y Polonia. Se trata de cuatro reportes de investigación y una tesis doctoral. Todos, desde diferentes miradas, indagan con niños y jóvenes aspectos asociados con cómo imaginan su porvenir.

En estos trabajos se reconocen dos ángulos de análisis. El primero focaliza al juego y su impacto en la imaginación del niño. Investigación a cargo de María Eugenia Villalobos en Colombia (2009).

El segundo hace visible los sueños, fantasías e imaginación del porvenir en niños y adolescentes. Magdalena Piorunek en (2007) investiga cómo toman decisiones sobre su futuro durante diez años en escuelas de Polonia. 
Presta y Almeida (2008) estudian cómo asimilan los jóvenes las desigualdades de oportunidades que viven en Brasil; por su parte, Shantal Messeguer de la Universidad de Granada, España (2012), explora la relación juventudes e imaginación; y finalmente, Chantal Royer (2009), en Quebec, indaga cómo se imaginan los adolescentes de 14 a 19 años sus futuras familias.

Estos trabajos se refieren a la capacidad de imaginación de niños y jóvenes; sin embargo, ninguno considera el sueño de porvenir en sí y mucho menos el acto de creación que éste representa, pero abren pistas que en este trabajo son profundizadas en el plano conceptual-metodológico sobre cómo favorecer los sueños de porvenir.

\section{Aspectos metodológicos}

El aporte de la perspectiva de investigación-intervención es que las herramientas engarzan lo conceptual y lo metodológico. Se arman al articular recursos etnográficos, con el análisis conceptual de discurso y el análisis institucional. Se diseñaron situaciones ex-profeso que sirvieron como instrumento de investigación, al mismo tiempo que propiciaron intervención. En esta perspectiva, el hacer investigación-intervención acentúa el registro y producción de experiencias que por el trabajo con el cuerpo y lo lúdico, disponen en un plano situacional las posibilidades de análisis. Por ello, modifica los procedimientos convencionales de la investigación educativa.

Los recursos utilizados fueron de observación participante, dispositivos lúdicos para propiciar la expresión de la condición imaginaria de los niños y niñas a través de dibujos, juegos de roles, ejercicios de crítica sobre escenarios de futuro, actividades lúdicas para reconocer formas de inscripción individual y grupal, y espacios de discusión.

La dinámica y los temas que surgían, se analizaron encadenando de forma táctica cada encuentro con los niños y niñas. Así la producción de conocimiento es simultánea para los y las participantes de la intervención como para quien interviene. Se sostuvo una concepción que reconoce a la emergencia y trayectos como figuras de intelección y, a su vez, como recursos metodológicos durante el proceso. 
El registro de experiencias obtenido a lo largo de 32 sesiones, se analizó construyendo una línea de tiempo en la que se mostró la forma como surgían los temas, que daban cuenta de los componentes duros de lo instituido, y las líneas que se trazaron como elementos de fuga que propiciaron el surgimiento de sueños de porvenir.

Un componente clave de la investigación-intervención es la figura de dispositivo, entendido como «[...] lo que somos (lo que ya no somos), y aquello que estamos siendo en el proceso de devenir» Deleuze (1989, p. 187) que operó como estrategia de análisis de las condiciones, pautas e imaginarios socioculturales que limitan o propician los sueños de porvenir, con el diseño de situaciones que inducen el cuidado de sí, el reconocimiento de la alteridad y un trabajo grupal reflexivo.

Para realizar este trabajo se eligió un grupo de horario vespertino de quinto año de primaria, que mostraba una gran variedad étnica, lingüística y cultural, al comprender niños citadinos mestizos y niños indígenas migrantes establecidos en las cercanías de la escuela.

\section{Aspectos conceptuales y hallazgos que permiten leer}

Esta investigación-intervención se sustenta con los conceptos de imaginario social instituyente e imaginación radical de Castoriadis (2002), para precisar procesos de subjetivación, emergentes y creativos que se enlazan en el terreno psíquico y social en los sueños de porvenir. Estos conceptos permiten observar las pautas, procesos y registros del imaginario social en el que se inscriben las historias de sueños realizados o no en sus familias, y la capacidad para soñarse de los niños y niñas, así como sus posibilidades de armar escenarios de porvenir.

\section{1 ¿Cómo definir el sueño de porvenir?}

Para la noción de sueños de porvenir retomamos los postulados de Castoriadis en Anzaldúa (2012, p. 31), quien «sostiene que la característica central del ser humano es su capacidad de crear figuras, formas, imágenes y que 
gracias a ellas se instituye a sí mismo e instituye a su sociedad». No se trata sólo de un proceso de adaptación a lo establecido socialmente, el sueño de porvenir es un recurso de poder crear figuras, formas e imágenes de nosotros mismos, en otros escenarios posibles y otras épocas históricas. Son representaciones que nos mueven del lugar establecido hacia escenarios anhelados y posiblemente realizables. En esta investigación-intervención, a través de las acciones lúdicas, se trabajó en el plano simbólico, y en la puesta en acto de ideaciones, pues no se corresponde linealmente con ideas pre-establecidas, por ello hay apertura para la elaboración de sueños por los niños y niñas en un escenario de porvenir.

Anzaldúa (2012) sostiene con base en Castoriadis, que el ser humano organiza su entorno creando formas y figuras que le dan un significado: «Esta capacidad imaginaria se manifiesta en el hombre como imaginación radical y en la sociedad como imaginario social» (p. 31). Por ende, el sueño infantil de porvenir puede considerarse como un primer ensayo para organizar y ordenar el mundo que nos rodea. En tal caso, se convierte en una función primordial sine qua non de socialización y, mientras esta función es suprimida o desbordada sin considerar sus afectaciones en las interacciones sociales, el individuo se pierde en un entorno cuyos significados no puede comprender.

Así, reconocemos en los sueños de porvenir un vehículo que contribuye al proceso de internalización que es consecuencia de la socialización. Berger y Luckman (2003) afirman que: «La sociedad, la identidad y la realidad se cristalizan subjetivamente en el mismo proceso de internalización» (p. 167). A través de la socialización se internalizan códigos cuyo dinamismo como elementos instituidos se ajusta a lo cultural y exigencias de vida, así como condicionantes de la época. Por esto, los seres humanos pasamos la vida aprendiendo no sólo nuevos códigos, sino también nuevos significados atribuidos a viejos códigos.

Entonces, si un individuo crece aislado no es capaz de comprender lo que sucede dentro de una sociedad, porque no conoce los significados. Explica Castoriadis (1975): «La auto-institución de la sociedad permite así recurrir a un nosotros que, sin designar a los individuos como conjunto, no se refiere sin embargo a nada más que a ellos (pero siendo constituidos en las mismas significaciones)» (p. 14). 
Este proceso se realiza mediante fuertes cargas emocionales, indispensables para que el aprendizaje sea efectivo: «Resulta innecesario agregar que la socialización primaria comporta algo más que un aprendizaje puramente cognoscitivo. Se efectúa en circunstancias de enorme carga emocional» (Berger y Luckman, 2003, p. 165).

Anzaldúa (2012) afirma que:

Los sujetos y las sociedades crean un mundo para sí, un mundo ensídico; de tal manera que lo que se entiende por mundo, es una elaboración propia de cada sociedad, es una creación de las significaciones imaginarias sociales de esta sociedad. (p. 32)

Desde la niñez practicaríamos la creación de la sociedad que nos condiciona, pero también en la que deseamos vivir, soñar sería un evento de suma importancia. Los sueños de porvenir abarcan distintas dimensiones y poseen la virtud de recrear cualquier aspecto de la vida.

Un sueño se despliega en un tiempo de sueño y crea, hace surgir un tiempo de sueño. Existe una temporalidad propia del sueño, así como, generalmente, una temporalidad propia del inconsciente. No es igual a nuestra temporalidad de adultos socializados, medio día puede hallarse antes de las 9 de la mañana, no importa, existe un antes/después. (Castoriadis, 1999, p. 5)

Pensar la experiencia de soñar el porvenir condujo a la interrogante: ¿Qué es la imaginación? Anzaldúa (2012) nos ayuda a hallar una respuesta: «La imaginación no es sólo la elaboración y conexión de imágenes [...] sino creación de imágenes (visuales, acústicas olfativas, táctiles, como significaciones para la psique» (p. 36). El sueño de porvenir se nutre con estas imágenes, las que cada persona transforma en otras posibilidades, todavía no realizadas, incluso proyecta su imagen plantada en ese escenario de forma diferente de cómo se visualiza en su presente, por ello es un acto de creación. Es una imaginación que trasciende el tiempo, el espacio, y tiene la capacidad de producir un imaginario social en devenir.

Entonces, ¿cómo comprender el concepto de imaginario social? Anzaldúa (2012, p. 32) responde basándose en Castoriadis, quien sostiene que las sociedades se construyen, pero también se autoalteran con aquel flujo ya descrito de las significaciones imaginarias creadas por ellas mismas, para auto organi- 
zarse y proveerse un entorno que corresponde al sentido y a la identidad que le han insertado.

[...] comprendí rápidamente que la historia y la institución de la sociedad eran obra de un imaginario instituyente, de un imaginario colectivo radical, paralelo a la imaginación creadora radical del individuo. Que por tanto cada sociedad se crea a sí misma y al crearse a sí misma crea un mundo propio. (Castoriadis, 2002, p. 88)

Las nociones conceptuales aquí descritas sirvieron de andamiaje para idear las situaciones lúdicas que servirían como recurso para la indagación, respecto a las tensiones entre los elementos y condicionantes instituidas que responden a la reproducción de lo social, pero a su vez, hacer visible o propiciar la producción de componentes de un imaginario instituyente, tanto en el plano colectivo, sostenido por el grupo de niños y niñas, como en orden de una creación individual.

\subsection{La idea de porvenir como trayecto}

Para entender esta estrecha relación entre el imaginario social instituido y la imaginación radical, se recurrió a planteamientos de Deleuze. Se observó que esta relación conforma un entramado, ambos se juegan al mismo tiempo y se influencian mutuamente, pero también están sujetos a movimientos, trayectos y procesos, lo que conduce a un devenir. El imaginario social muestra lo que es real en este momento histórico, sin embargo, la imaginación radical tiene siempre la capacidad de rebasarlo, y darle nuevos sentidos, incluso de salir totalmente de lo establecido creando nuevos caminos.

Por esta razón, no se habla de futuro, ya que este concepto nos remite a una idea de algo que tiene que suceder, mientras que el concepto porvenir se refiere a una idea de trayecto hacia un devenir que dependerá de las elecciones del sujeto. El devenir es siempre dinámico. Deleuze (1993) nos habla de estos trayectos, movimientos, procesos: «Pero un medio está hecho de cualidades, sustancias, potencia y eventos...» (p. 81).

Decidir seguir un trayecto es apenas el punto de partida del recorrido. Es el primer evento, a partir del cual, este trayecto está sujeto a encuentros y 
desencuentros, eventos favorables y desfavorables, bifurcaciones y recovecos que operan como un continuo devenir. Una persona que no construye consciencia de sí escoge trayectos sin involucrar su responsabilidad ni medir las repercusiones en su propia vida y la de otros.

La intensidad expresada en la emergencia, indeterminación, el trayecto, los ejercicios cartográficos, en el hacer itinerario y mapear la apertura a lo contingencial y cómo en el devenir se arman rutas, es lo que hace inteligible a los movimientos de creación y alteración que se producen en el quehacer de la investigación enlazada con la intervención educativa. (Negrete, 2017, p. 6)

Lo importante fue conducir a los niños y niñas participantes en esta investigación-intervención educativa, mediante actividades lúdicas, espacios de discusión y reflexión, a tomar decisiones sobre los trayectos que eligen, liberándose de las líneas sedimentadas que operaban como limitantes de sus sueños.

\subsection{Las líneas sedimentadas que limitan sus sueños}

Los sueños de porvenir se nutren con la imaginación radical que opera como líneas de fuga de aquellos componentes que están sedimentados y fijos. Abrir espacios que posibiliten al individuo para crear paisajes hipotéticos e incluirse, él mismo, observándose dentro de estos paisajes, fue parte de los ejercicios de indagación e intervención. Por ende, era inminente para crear dichos paisajes, convocar a través de juegos, al imaginario social instituido y, hacer ver y hablar a los niños y niñas de aquello que se tensiona con lo instituyente del momento histórico y del territorio en donde viven. Dichas tensiones dieron la pauta para reconocer qué elementos propiciaban o limitaban imaginar este porvenir y la capacidad de soñarlo de los niños y niñas.

Así se expresaron las niñas:

- Las celan demasiado sus papás y hermanos.

- Sus padres no les dan permiso para salir al parque con sus amigas, porque son incapaces de cuidarse solas.

- No les dan libertad, las controlan demasiado.

- No tienen permiso de tener novio hasta los 18 años. 
- Les exigen tener buenas calificaciones más que a sus hermanos.

- Tienen que hacer la limpieza en la casa, si no las golpean o las castigan.

- Tienen que atender a sus hermanos.

El trabajo analítico realizado a lo largo del proyecto se hizo en dos planos. Uno que permitía registrar y valorar lo que acontecía en cada encuentro con los y las infantes y con ello, idear la situación de indagación lúdica para el siguiente encuentro, con el propósito de profundizar en aspectos que iban emergiendo en el decir de niños y niñas o cómo los ponían en relieve mediante los juegos. Y por otro lado un ejercicio retrospectivo que llevó a analizar los datos obtenidos a lo largo de las actividades realizadas en estos dos ciclos escolares.

Los componentes que trazaban líneas sedimentadas y operaban como elementos limitantes para el sueño de porvenir refieren a elementos anclados con pautas de socialización e imaginarios socioculturales que los niños y niñas habían internalizado. Al mismo tiempo, con las actividades lúdicas de indagación se inducía a la producción de vivencias y experiencias que conducían al cuidado de sí, el reconocimiento de la alteridad y un ejercicio grupal reflexivo. Así, se fueron interrelacionando unos componentes con otros estableciendo entramados que dieron pie a los trayectos de porvenir según las siguientes categorías:

a) la discordia, la agresividad y la soledad de algunos chicos condujo a crear actividades para fomentar la alteridad y el imaginario grupal;

b) la discriminación de género y étnica manifiesta en el decir y en las vivencias con los y las infantes, llevaron a idear situaciones para hacer circular la voz a niñas y a niños indígenas sobre sus lugares de procedencia, sus historias de vida y así reconocer la diversidad de mundos jugándose en el grupo;

c) la pobreza y el abandono como lugares recurrentes de imposibilidad, de tristeza, pasaron por situaciones lúdicas en la configuración de paisajes en los que se miraba cada uno y, a su vez, eran construidos con el conjunto de voces del grupo;

d) este encadenamiento, trastocaba indudablemente las relaciones con su entorno. 
Se puede afirmar entonces, que los sueños de porvenir no son estáticos. Dependen de los trayectos elegidos y desde los cuales los sujetos transitan. En este proyecto fue patente que los y las menores participantes trazaron caminos, desde los sentires que experimentaron en cada momento, las bifurcaciones que tomaron, las marcas que dejaron en su camino aquellos seres que forman parte de su biografía. En sus vivencias y las decisiones sobre sus escenarios de vida, alcanzaron a traspasar los límites de lo instituido y de sus propios deseos por seguir adelante y la decisión de hacerlo o no; lo cual les sirvió para que trascendieran estos límites sociales, familiares, de género, étnicos, de lenguaje, etc. Ahora falta entender qué es y cuáles son los alcances de la intervención educativa.

\section{Aporte de la investigación-intervención educativa en sueños de porvenir}

a) El trabajo in situ. La indagación/cambio en lo grupal y en trayectos elegidos

Aquí, se trata de presentar cómo se concibe la investigación-intervención educativa desde la experiencia de los resultados obtenidos, y dar cuenta de por qué responde a lo emergente, a lo no expresado, a lo que brota en intersticios dentro de lo instituido. En segundo lugar, se demuestra cómo se enlaza la relación entre investigación e intervención educativa, reconociendo cómo atiende a la demanda que se observó, los temas que surgieron, su tratamiento, y el acompañamiento analítico conceptual. Finalmente, se analiza el acto de intervención, su impacto, en todos los participantes: los niños, niñas y la interventora.

Negrete (2009) afirma que «la intervención se gesta a partir de la identificación de un problema, de una necesidad o de una demanda de apoyo, etc.» (p. 6). Y nos explica que el diagnóstico representa la mejor herramienta para detectar estas demandas, de aquello que va surgiendo a través del hacer lúdico y el decir, respecto de lo que pasó en cada situación de indagación, va tomando forma una intervención educativa, ejerciendo un análisis apuntalado 
conceptualmente y creando situaciones in situ para encadenar y reconocer los sentidos de cambio y permanencia al finalizar el proceso.

Para realizar esta investigación-intervención, fue necesario ajustarse a las condiciones del lugar. El interés por indagar y propiciar sentidos de cambios desde la voz de los niños y niñas condujo a que el proceso de investigación-intervención estuviera abierto a lo que acontecía y no a una planeación estructurada. Esta condición propició la invención de juegos y actividades como instrumentos de investigación atingentes a las necesidades y los temas emergentes que representaban problemáticas específicas para los participantes y una construcción conceptual.

La investigación-intervención educativa opera como dispositivo de indagación y de cambio, ya que mediante ésta, se dio la palabra a los participantes y se escuchó lo que expresaron, se observó sus reacciones que develan marcas y huellas respecto a las líneas de poder, saber y subjetividad puestas de relieve en las actividades. También se reconoció en los distintos trayectos de estas líneas, los temas que eran recurrentes, se trajeron al terreno de lo que se dice, convirtiéndolos en problemas inminentes que exigían ser analizados y tratados. Todo lo anterior muestra el engarce entre investigación e intervención educativa en un proceso muy complejo.

Se habla de despliegue de un proyecto de investigación-intervención (Negrete, 2009) en el momento en que se hacen patentes los deseos de la población intervenida; con los niños y niñas, sus deseos y preocupaciones propiciaron que un ejercicio circunscrito a unos meses, se extendiera durante dos ciclos escolares ( $5^{\circ}$ y $6^{\circ}$ grado), y se hizo obvio que la intervención educativa, constituida en el vínculo investigación-intervención posibilitó a todos los participantes (niños, niñas y a la interventora) una nueva visión desde las experiencias producidas.

La investigación-intervención educativa favoreció abrir los ojos, para usar herramientas que tenían, pero no sabían cómo utilizar. La apertura a la imaginación y a trazar caminos para hacer lo imaginado, les permitió ampliar sentidos para sus vidas. Los trayectos escogidos fueron:

- Cómo desea vivir y en qué tipo de entorno.

- A qué desea dedicarse, una profesión, un oficio. 
- Cómo quiere formar su familia, cuántos hijos desea tener.

- A qué ideales pretende dedicar su tiempo

- En qué tipo de país desea desarrollarse.

- Qué ciudadano/ciudadana será.

Las primeras actividades fueron difíciles debido a la poca cohesión que presentaba el grupo. Formar equipos fue bastante complicado porque varios participantes tenían conflictos entre sí. Esta situación condujo a trabajar con ellos la idea de alteridad, desde la aceptación del otro con sus diferencias. Para la investigación-intervención, la condición de una mentalidad grupal es un medio indispensable, porque además, el grupo opera como pantalla que interpela la imaginación, otorga acompañamiento y establece lazos de afiliación que arman un espacio alterno a las condiciones de vulnerabilidad en las que se situaban estos chicos y chicas.

Por ello, los conceptos y el trabajo metodológico respecto a la alteridad y grupalidad fueron puestos en escena con actividades que los niños participantes aplicarían en la relación diaria. Se analizó la alteridad con base en el concepto de Rostros de Lévinas (1971): «El rostro está presente al rehusar ser contenido» (p. 211); y con Ana María Fernández (2013) el concepto de grupalidad: «Los grupos no son lo grupal» (p. 19).

\section{b) La discriminación de género y étnica}

Un tema que se hizo patente en el decir y hacer de los niños y niñas fue la discriminación tanto de género como étnica. El análisis de los discursos se sustentó con el texto de Bourdieu (1990): «La dominación masculina. Se demuestra que la situación de "machismo", que prevalece hasta hoy en día, se basa sobre todo en aprendizajes culturales. Es un discurso repetido. Nos dice Bourdieu (1990) que en general ningún pueblo ha buscado una verdadera justificación a este hecho:

La dominación masculina está lo suficiente asegurada por lo que no le hace falta una justificación: puede solamente ser y enunciarse en las prácticas y los discursos que nombran el ser por encima de la evidencia, coadyuvando a que sea conforme a lo enunciado. (p. 5) 
Todo parte de una simple observación: los genitales masculinos son exteriores y los femeninos interiores. Se crea así un clivaje hombre-mujer, que lleva a las sociedades mediterráneas a relacionar lo masculino con lo exterior, con el sol, lo público, el derecho, el trabajo fuera de casa, con las acciones espectaculares y peligrosas, mientras que lo femenino se compara como lo escribe Bourdieu (1990) con:

[...] el interior, lo húmedo, lo bajo, lo curvo, lo continuo, se les atribuye a las mujeres todos los trabajos domésticos, es decir ocultos y del dominio de lo privado, inclusive invisibles o vergonzoso, tales como la crianza de los niños y de los animales, así como una buena parte de los trabajos exteriores, particularmente todos aquellos que se relacionan con el agua, la hierba, [...] especialmente los más sucios (el acarreo del estiércol), los más monótonos, los más cansados y los más humildes. (p. 8)

Esta situación conduce a la emergencia y permanencia de sociedades marcadas por la dominación masculina, dejando de lado la inteligencia y creatividad que se asocia con lo femenino, produciendo un juego de poder donde las mujeres se constituyen en vínculos de dependencia, sin esperanza de poder existir, con márgenes de decisión totalmente limitados. Desde el momento en que el papel de la mujer es somatizado, ella considera natural asumir esos roles, supeditados al poder patriarcal, y participa en su reproducción puesto que la primera educación de su hijo depende de ella. Es quien inculca las reglas culturales a hijos e hijas, les enseña cómo comportarse, qué actitudes y qué lenguaje convienen a su género y, así perpetúan la dominación del macho.

Estas aseveraciones fueron reconocidas en imaginario social instituido, que se sostenía con el grupo y propició analizar las ideas, creencias y prejuicios aceptados como normales en la estructura social en donde están inmersos los y las participantes y reconocer:

a) Las pautas culturales de su clase social respecto a ser mujer, lo que les es permitido o no.

b) Lo que el mismo imaginario social considera que debe ser un varón.

c) Las ideas de la sociedad citadina respecto a los indígenas.

d) La importancia que su sociedad le da al entorno. 
Al reconocer estos elementos, se diseñaron situaciones con las que los niños y niñas reconocieran la alteridad y los sentidos de la diferencia.

Con las proposiciones de Judith Butler se hizo un análisis del discurso con mayor complejidad. Esta autora nos hizo notar la dimensión política del discurso. Butler (2007, p. 47) afirma que:

En definitiva, la construcción política del sujeto se realiza con algunos objetivos legitimadores y excluyentes, y estas operaciones políticas se esconden y naturalizan mediante un análisis político en el que se basan las estructuras jurídicas.

El género es una creación psico-social expresada mediante un discurso. La especie humana ha creado el género, determinando así, quiénes son sujetos de poder y quiénes son dominados. Por ende la discriminación es producto del miedo, miedo a lo diferente, a no comprender, y la discriminación hacia la mujer es una forma de temor que ha llegado a extremos. ¡El miedo se convirtió en odio! Es la única manera de comprender el maltrato sistemático que ha sufrido este género $\mathrm{y}$, cotidianamente, observan en su entorno los niños y niñas de este proyecto.

Fue necesario trabajar con los niños sobre los dichos y proverbios que fungen como anclajes de conducta en su entorno social. Las niñas se enfrentan en todo momento con expresiones tales como: «calladita te ves más bonita» $\mathrm{y}$ exigen que sus opiniones sean escuchadas.

En segunda instancia se abordó el análisis de la discriminación étnica, y fue preciso definir quiénes eran provenientes de poblaciones indígenas o pueblos autóctonos de la región.

La discriminación hacia la mujer y hacia los pueblos originales se observa desde que existen registros históricos y quizás desde antes. Una definición de discriminación se hace urgente y la siguiente es del CONAPRED (2011):

La discriminación es una práctica cotidiana que consiste en dar un trato desfavorable o de desprecio inmerecido a determinada persona o grupo, que a veces no percibimos, pero que en algún momento la hemos causado o recibido. (p. 1)

La discriminación étnica se hizo manifiesta en las distintas actividades desarrolladas. Los chicos indígenas eran a menudo agredidos con frases y 
dichos tales como «indio pata rajada» o «te bajaron del cerro», «ide a tiro indio!». Quienes tienen como lengua materna el náhuatl preferían no hablarla porque alegaban que solamente la emplean cuando van a su pueblo. Estas consideraciones así como actitudes de sospecha o desconfianza hacia los niños o niñas por sus rasgos étnicos fueron trabajadas en la intervención desde los planteamientos de alteridad y diferencia.

Las familias indígenas que migran a Tepoztlán, viven un continuo duelo: por haber abandonado su pueblo donde quedaron sus familiares, el panteón en donde descansan sus antepasados, y luego, porque en la ciudad sólo encontraron rechazo, desempleo, escasez, promiscuidad, es decir, miseria. En esta condición soñar un porvenir diferente no es cosa fácil, sobre todo si falta una característica más: la condición de miseria que se estudia en el siguiente apartado.

\section{c) La condición de miseria instrumentada por el Estado}

Afirma Mallard (2009, p. 6) que las nociones de pobreza y de miseria se refieren a dos fenómenos sociales de naturaleza muy diferente. Los economistas definen la miseria con base en los recursos que una persona dispone al día, y fijan el umbral de la pobreza extrema en dos dólares al día. Sin embargo, no toda persona pobre se encuentra en condición de miseria y esto depende de la sociedad en donde vive, el entorno, o de una condición elegida por razones espirituales, etc.

Desde el siglo pasado, se ha extendido la ideología Neoliberal promovida por las sociedades anglosajonas, que consiste en dar todas las facilidades al capital, suponiendo que va a crear empleos. Trataron de imponerla en el mundo entero, y particularmente en América Latina. Según Bourdieu (1998), el Neoliberalismo es: «Un programa de destrucción de las estructuras colectivas que sean capaces de obstaculizar la lógica del mercado puro» (p. 3). Así, nos cantaron las maravillas de este sistema, diciéndonos que la globalización del mercado reduciría la pobreza. Y la pobreza se ha incrementado, quizás porque al imponer esta visión, sólo se consideró los intereses de los dueños del capital. 
La vulnerabilización, no obstante, afirma Fernández (2013) :

[...] nada de lo social es homogéneo. Con esta expresión he querido subrayar que los dispositivos que operan eficazmente en la vulnerabilización [...] actúan desde distintos focos del tejido social asemejando y diferenciando sus operatorias según se trate de varones o mujeres, según pertenezcan a sectores medios-altos o pobres o marginales rurales o urbanos, blancos descendientes de europeos o de ascendencia afro o de pueblos originarios, heterosexuales o inscriptos en las llamadas diversidades sexuales, etc. (p. 12)

La condición de miseria y vulnerabilización fue evidente a lo largo del proyecto, $y$, desde nuestro punto de vista presenta varias dimensiones entrelazadas entre sí:

- Orgánica y psíquica: vía los ejercicios con chicos y chicas, se analizó el impacto de la miseria en el cuerpo y sus percepciones de sí mismos en relación con las personas que la viven. Las condiciones de malnutrición limitan el potencial y el desarrollo de las capacidades del niño.

- Intelectual: muchos de los participantes son hijos que proceden de hogares precarios, cuyos padres muestran procesos truncos en la escolaridad, poseen un lenguaje básico y con pautas de socialización sujetas a la violencia.

- Imaginario filosófico-religioso: la espiritualidad con la que se entablan reificaciones desde «una deidad o un santo» como fuentes de resignación o esperanza. De tal forma que los actos de su vida, están permeados por estos componentes.

- Del entorno: al situarse en los espacios marginales, su vida se inscribe en el deterioro ambiental.

Hogares monoparentales, padres con escasa formación, muchos sin un trabajo fijo, habitando en viviendas precarias en barrios en donde domina la violencia. En un clima de criminalización, porque el Estado los equipara a delincuentes en potencia. Su pobreza los hace doblemente vulnerables: primero a las carencias causadas por la pobreza misma y que la falta de ayuda por parte del Estado agrava, y segundo porque éste los considera culpables de su propia pobreza. 


\section{Conclusión}

Los sueños de porvenir tomaron lugar cuando los niños y niñas fueron desmontando las significaciones sostenidas por imaginarios instituidos que aludían a su condición de miseria, género, etnia, individualidad, subordinación, precariedad, entre otros, que obturaban sus posibilidades de soñar. Los niños participantes en esta investigación-intervención fueron capaces de crear escenarios alternos de porvenir en cada una de estas dimensiones mediante vivencias y experiencias grupales que los apuntalaban. La intervención-educativa se coloca en el lugar de producir experiencia y, mediante la ejercitación de los escenarios imaginados, siembra trayectos de posibilidad en la biografía de esos niños y niñas de quinto y sexto año para que puedan crear sus propios proyectos de vida.

El esquema Neoliberal ha creado niveles inauditos de pobreza en todos los países, lo cual ha propiciado la condición de miseria, precariedad y vulnerabilidad en la que se desenvuelve la sociedad en donde están inmersos los niños y niñas participantes, y soñar el porvenir, colocarse en escenarios distintos, constituye una herramienta que disloca esta condición al configurar rutas y trayectos que ofrecen otros escenarios.

El principal hallazgo es que mediante el sueño grupal de vivir en un país más justo, se hacía visible en el trato cotidiano entre ellos, reconociendo los actos éticos de reconocimiento de sus posibilidades de ser y de cuidado de sí. Valorando las diferencias por su condición de género, su etnia o su lengua. Niños y niñas se crearon un mundo posible, en devenir. En contraparte a la condición de vulnerabilidad en la que han sido colocados por una estructura capitalista neoliberal.

\section{Referencias}

Anzaldúa, R. E. (2012), Lo imaginario como significación y sentido. En Anzaldúa R. E., México: Universidad Pedagógica Nacional. Imaginario social, creación de sentido. (pp. 30-62).

Berger, P. y Luckman T. (2003). La construcción social de la realidad. Buenos Aires : Amorrortu editores. 
Bourdieu, P. (1998). L'Essence du Neolibéralisme. Paris : Le Monde Diplomatique.

- (1990). «La domination masculine». In: Actes de la recherche en sciences sociales. Vol. 84, septembre 1990. Masculin/féminin-2. pp. 2-31. DOI: 10.3406/arss.1990.2947

Butler, J. (1997). El género en disputa. Barcelona -Buenos Aires -México: Editorial Paidos.

Castoriadis, C. (2002) La insignificancia y la imaginación: Diálogos SA. Madrid: Editorial Trotta.

— (1999). Entretien avec Cornelius Castoriadis. Carrefours du Labyrinthe. Volume vi. Paris : Seuil.

- (1975). L'institution Imaginaire de la Société. Paris. Éditions du Seuil, collection « Esprit »,

Conapred, (2011). Documento informativo sobre la discriminación racial en México.

Deleuze, G. (1993). Critique et clinique. Paris: Éditions Minuit.

- (1989), «Qu'est-ce qu'un dispositif ? », rencontre internationale (9-11 janvier 1988), Foucault Michel philosophe, Paris : Seuil, p. 185195.

Fernandez, A. M. (2002). El campo grupal. Notas para una genealogía. Buenos Aires: Ediciones Nueva Visión.

Lévinas, E. (1971). Totalité et Infini: Essai sur l'extériorité. Paris : Le Livre de poche, biblio essais.

Mallard, B. (2009). Le paradoxe de la négation de la misère. Alpes, Grenoble. France : Les éditions du CNRS, Maison des Sciences de l'Homme -

Messeguer, S. (2012). Imaginarios de futuro de la juventud rural Educación Superior Intercultural en la Sierra de Zongolica. Tesis doctoral. Universidad de Granada. España. Disponible en línea: http://www.intersaberes.org/wp-content/uploads/2013/02/tesis-doctoral-Shantal.pdf

Negrete, T. (2017). Dos perspectivas para conceptualizar y diferenciar la relación entre investigación e intervención educativa en contextos de emergencia. México Congreso Nacional de Investigación Educativa (COMIE).

- (2009). El campo de la intervención educativa: soportes analíticos y experiencias de interventores. México: $\mathrm{X}$ Congreso Nacional de Investigación Educativa. 
ONu (2010). Droits des Minorités: Normes Internationales et indications pour leur mise en æuvre.

Pioruner, M. (2007). L'élaboration des projets à l'adolescence : étude empirique auprès d'adolescents polonais. Revista.org : L'orientation scolaire et professionnelle 36/2 | DOI : http://osp.revues.org/1409. DOI : 10.4000/osp.1409*

Presta, S. y Almeida, A. M. (2008). Fronteiras imaginadas: experiências educativas e construção das disposições quanto ao futuro por jovens dos grupos populares e médios. Brasil : Educ. Soc., Campinas, vol. 29, n. 103, (p.p. 401-424). Disponível em http://www. cedes.unicamp.br

Royer, C. (2009). Les jeunes et leur avenir: une analyse de leurs projets familiaux. Enfances, Familles, Générations. Numéro 10. p.35/37. Université de Montréal. DOI: 10.7202/037519ar ; http://id.erudit. org/iderudit/037519ar*

Villalobos, M. E. (2009). El rol del maestro frente a la construcción del juego simbólico en los niños. Diversitas vol.5 no.2. Perspect. Psicol. / ISSN: 1794-9998 / Vol. 5 / (pp. 269-282), Colombia

NOTA: Las traducciones del francés, del inglés y del portugués al español fueron hechas por la autora. 